\title{
Functionalization of Bentonite and Vermiculite after the Creation of Structural Defects through an Acid Leaching Process
}

\author{
Dorsan S. Moraes, ${ }^{* a}$ Lucas C. R. Miranda, ${ }^{b}$ Rômulo S. Angélica, ${ }^{a}$ \\ Geraldo N. Rocha Filho ${ }^{c}$ and José R. Zamian ${ }^{c}$ \\ ${ }^{a}$ Instituto de Geociências, Universidade Federal do Pará(UFPA), 66075-110 Belém-PA, Brazil \\ ${ }^{b}$ Instituto de Geociências e Engenharia, Universidade Federal do Sul e Sudeste do Pará (UNIFESSPA), \\ 68505-080 Marabá-PA, Brazil \\ 'Instituto de Ciências Exatas e Naturais, Universidade Federal do Pará (UFPA), \\ 66075-110 Belém-PA, Brazil
}

\begin{abstract}
The synthesis and use of functionalized materials is growing every year. Thus, this work presents a methodology for the functionalization of bentonite and vermiculite after the acid leaching of the raw materials. Leaching was performed with sulfuric acid $\left(\mathrm{H}_{2} \mathrm{SO}_{4}\right)$, and the functionalization was performed with (3-mercaptopropyl)trimethoxysilane (MPTS), which was oxidized after being anchored to the support. Compared to the results in the literature for directly functionalized raw bentonite, the materials had a greater number of anchored propyl sulfonic acid groups, and the greatest number of these groups led to an increase in the acidity of the raw materials. The raw and functionalized bentonite and vermiculite were characterized by X-ray diffraction (XRD), energy dispersive X-ray (EDX), thermogravimetric analysis (TGA), $\mathrm{N}_{2}$ adsorption and the surface acidity was determined by acid-base titration.
\end{abstract}

Keywords: geochemistry, inorganic synthesis, clays

\section{Introduction}

Clays have been used for human benefit since prehistory. These materials exhibit potential as raw materials in the areas of the catalysts, catalysts support, adsorbents and others technologies fields because of their small particle sizes $(<2 \mu \mathrm{m}){ }^{1}$

Paleozoic sedimentary basins occupy 50\% of Brazilian territory. These basins have the potential for the occurrence of different clay deposits with different mineral types. Thus, the discovery of new occurrences and the characterization of clay deposits are driving researchers to work with these materials in areas of industrial interest, such as catalysis. ${ }^{2-4}$

The utilization of clay minerals as catalysts began in the 1930s with the use of acid leached montmorillonites in catalytic cracking of petroleum. ${ }^{5}$ Additionally, the ability to modify the structure of these materials allowed that these substances were used as catalysts in heterogeneous processes. ${ }^{6-8}$ In this way, the optimization of the acidification processes and the creation of organoclays are examples of

*e-mail: dorsan@ufpa.br the search for better performance of these natural materials in the preparation of more efficient and effective catalysts. ${ }^{4,9}$

This process is so interesting that other phyllosilicate material, such as vermiculites, which are minerals with similar structures and properties, in some cases superior, to clay minerals, are also being studied for use in catalysis. ${ }^{10}$

In studies of organofunctionalized clays, the literature shows that acid leaching before the insertion process increases the number of active sites on the surface of the material through the creation of structural defects in the tetrahedral sheets and also by replacement of exchangeable cations by protons. This substitution favors an increase in the number of organic groups fixed on the surface of support. ${ }^{11}$

In this way, the main purpose of this work is to increase the number of active sites in the structure of a vermiculite and raw bentonite from the Amazon through an acidic leaching process. ${ }^{2}$ The aim is to obtain a greater number of anchor points for a functionalizing agent, (3-mercaptopropyl)trimethoxysilane, in the natural material. The anchored mercaptopropyl groups (-SH) are then oxidized to $-\mathrm{SO}_{3} \mathrm{H}$ groups. ${ }^{9}$ 
Vermiculite is investigated to examine the possibility of reutilization of this material, which is usually discarded. Thus, we seek alternatives in the preparation of adsorbents or heterogeneous catalysts at relatively lower costs to create investment possibilities for the north of Brazil, which is less industrialized than the south of the country. ${ }^{12,13}$

\section{Experimental}

Preparation of the functionalized materials

Two types of phyllosilicates structures were utilized in the preparation of the functionalized materials: a bentonite from the Amazon region, described by Moraes et al. ${ }^{2}$ as Balsas bentonite, the structural formula of the main clay mineral present in it composition is $\mathrm{K}_{0.33} \mathrm{Ca}_{0.05} \mathrm{Na}_{0.03}\left(\mathrm{Al}_{1.34} \mathrm{Mg}_{0.41} \mathrm{Fe}_{0.26} \mathrm{Ti}_{0.03}\right)\left[(\mathrm{OH})_{2} /\right.$ $\mathrm{Al}_{0.19} \mathrm{Si}_{3.81} \mathrm{O}_{10}$ ], and a vermiculite from Santa Luzia (Paraiba State, Brazil). The chemical proportions of the constituents (at.\%) were $\mathrm{SiO}_{2}, 42.74 ; \mathrm{Al}_{2} \mathrm{O}_{3}, 16.08 ; \mathrm{Fe}_{2} \mathrm{O}_{3}, 12.65 ; \mathrm{K}_{2} \mathrm{O}$, 1.09; $\mathrm{MgO}, 23.27 ; \mathrm{CaO}, 1.38 ; \mathrm{NiO}, 0.18 ; \mathrm{Cr}_{2} \mathrm{O}_{3}, 0.49 ; \mathrm{TiO}_{2}$, 2.01 and $\mathrm{MnO}_{2}, 0.11$, which is normally used as adsorbent in chemical packaging.

The acid leaching was carried out with analytical grade sulfuric acid (Merck). The treatment was applied to the bentonite with different durations $(2,4$ and $6 \mathrm{~h})$ and concentrations $\left(2,4\right.$ and $\left.6 \mathrm{~mol} \mathrm{~L}^{-1}\right)$ to verify the modifications of the starting material and the choice of the best conditions of treatment.

At room temperature, $1 \mathrm{~g}$ of bentonite was dispersed in $10 \mathrm{~mL}$ of sulfuric acid and stirred. After the necessary time, the materials were extensively rinsed with deionized water until the $\mathrm{pH}$ was neutral; dried at $60{ }^{\circ} \mathrm{C}$, pulverized, and stored in a desiccator for further characterization. This bentonite was denoted H-bentonite.

The untreated sample of vermiculite was attacked with $\mathrm{H}_{2} \mathrm{SO}_{4}\left(2 \mathrm{~mol} \mathrm{~L}^{-1}, 4 \mathrm{~h}\right)$; this material was denoted $\mathrm{H}$-vermiculite.

The functionalizing agent was (3-mercaptopropyl) trimethoxysilane (MPTS) (Aldrich). Analytical grade toluene (Synth) was utilized as a material dispersant and as a solvent for the functionalizing agent. The excess MPTS, which was not anchored on the materials, was extracted with analytical grade ethyl ether (Synth) and dichloromethane (Merck). $\mathrm{H}_{2} \mathrm{O}_{2}(35 \%)$; analytical grade ethanol (Nuclear) and $\mathrm{H}_{2} \mathrm{SO}_{4}$ (Merck) were utilized in the oxidation and acid activation of the functionalizing agent anchored on the surfaces of the bentonite and vermiculite.

The functionalization process for the sample, occurred after the leaching process, followed the procedure described by Moraes et al..$^{9}$ Initially, the material was dried at $110^{\circ} \mathrm{C}$ for $24 \mathrm{~h}$; then, $5 \mathrm{~g}$ of the sample was dispersed in a functionalizing solution ( $10 \mathrm{~g}$ of MPTS in $250 \mathrm{~mL}$ of dry toluene). The dispersion was agitated for $8 \mathrm{~h}$ and refluxed for $24 \mathrm{~h}$. After extraction in a Soxhlet extractor with a mixture of $\mathrm{CH}_{2} \mathrm{Cl}_{2} / \mathrm{Et}_{2} \mathrm{O}(50 / 50 \mathrm{~mL})$, the purified solid material was filtered and dried in air. The materials obtained were denoted H-bentonite-SH and $\mathrm{H}$-vermiculite-SH.

The anchored -SH groups were oxidized by immersing the materials in a solution of $\mathrm{H}_{2} \mathrm{O}_{2}(10.2 \mathrm{~mL})$ and $\mathrm{MeOH}$ $(24.4 \mathrm{~mL}$ ) for $24 \mathrm{~h}$. The oxidized material was then rinsed with $\mathrm{H}_{2} \mathrm{O} / \mathrm{EtOH}(50 / 50 \mathrm{~mL})$ and again dispersed in $0.1 \mathrm{M} \mathrm{H}_{2} \mathrm{SO}_{4}(4 \mathrm{~h})$; the redispersed material was extensively rinsed with deionized water until the $\mathrm{pH}$ was neutral, dried at $60^{\circ} \mathrm{C}$, and stored in a desiccator for further characterization. After this process, the materials were denoted as $\mathrm{H}$-bentonite- $\mathrm{SO}_{3} \mathrm{H}$ and $\mathrm{H}$-vermiculite- $\mathrm{SO}_{3} \mathrm{H}$.

\section{Characterization}

The raw, acidified and functionalized samples were characterized by X-ray powder diffraction (XRD). The bentonite X-ray diffraction pattern were obtained with a PANalytical X'Pert PRO MPD (PW3040/60) diffractometer using nickel-filtered $\mathrm{CuK} \alpha(\lambda=1.540598 \AA)$. For the analysis, the following conditions were used: tension, $40 \mathrm{kV}$; current, $30 \mathrm{~mA}$; scan range between 3 and $30^{\circ}$; step size, $0.016^{\circ}$; continuous scan mode and counting time of $99.7 \mathrm{~s}$. The oriented samples were prepared according to the procedures described in Tributh and Lagaly. ${ }^{14}$ For the vermiculite sample, the scan range was 5 to $75^{\circ}$ in an unoriented mount.

Thermal decomposition studies (thermogravimetric analyses, TGA) of the samples were performed with a thermogravimetric analyzer (Shimadzu Model DTG-60H). The measurements were carried out on $20 \mathrm{mg}$ of sample using alumina crucibles and $\mathrm{N}_{2}$ atmosphere $\left(40 \mathrm{~cm}^{3} \mathrm{~min}^{-1}\right)$ with a heating rate of $20{ }^{\circ} \mathrm{C} \mathrm{min}-1$ from room temperature to $1000{ }^{\circ} \mathrm{C}$.

The chemical proportions of the constituents in the raw sample and after the acid leaching process were determined by energy dispersive X-ray (EDX) fluorescence spectrophotometry in a Shimadzu device, model EDX-700, under a helium atmosphere.

The presence of sulfur in the samples was also determined by energy dispersive $\mathrm{X}$-ray fluorescence spectrophotometer under the same analytical conditions. The sulfur presence is an indirect indicator of the number of propylsulfonic groups anchored to the support because each MPTS chain has a sulfur atom in its structure.

Micromeritics TriStar II model 3020 V1.03 apparatus was used to determine the nitrogen adsorption/desorption 
at $-196{ }^{\circ} \mathrm{C}$. The specific surface areas (SSA) and total pore volumes $(\mathrm{Vp})$ of the samples were obtained with the BET (Brunauer-Emmett-Teller) and BJH (Barrett-JoynerHelenda) methods, respectively.

The determination of the surface acidity by acid-base titration followed the procedures described by Dijs et al. ${ }^{15}$ The procedure consisted of the suspension of $0.5 \mathrm{~g}$ of solid material in $50 \mathrm{~mL}$ of $0.1 \mathrm{~mol} \mathrm{~L}^{-1} \mathrm{KCl}$ solution. The solution was agitated for $20 \mathrm{~min}$ and titrated with $0.2 \mathrm{~mol} \mathrm{~L}^{-1} \mathrm{KOH}$ in the presence of phenolphthalein.

\section{Catalytic tests and product characterization}

For comparison, the catalytic tests followed the procedure described by Moraes et al. ${ }^{9}$ In each test, $2.3 \mathrm{~g}$ of each catalyst was used for the esterification reaction of $30 \mathrm{~mL}$ (524 mmol) of acetic acid with $39.5 \mathrm{~mL}$ ( $524 \mathrm{mmol})$ of propan-1-ol. The reaction was carried out in a $250 \mathrm{~mL}$ round-bottom flask under agitation and reflux. The conversion of the reactants to products was monitored with the AOCS method (which measures the total acidity of the reaction mixture to evaluate the conversion of reactants). ${ }^{16}$ After two hours, $0.5 \mathrm{~g}$ of the analyte was titrated with $0.5 \mathrm{~mol} \mathrm{~L}^{-1} \mathrm{KOH}$ solution in the presence of phenolphthalein. After 14 hours of the reaction the produced ester (non polar phase) was separated from the reactants (polar phase) by rinsing with deionized water. The catalyst was recovered by filtration, rinsed with methanol and dried at $60{ }^{\circ} \mathrm{C}$.

To compare the performance of the catalysts, a reaction was carried out under the same conditions, but using Amberlyst 36, an organic polymer often used in studies of reactions catalyzed by acids.

\section{Results and Discussion}

The powder X-ray diffraction patterns (Figure 1) of the raw $(\mathrm{Ba})$, acidified $(\mathrm{Bb})$ and functionalized bentonite $(\mathrm{Bc})$, show the characteristic reflections of montmorillonite, the prevailing clay mineral; illite and quartz were observed in the raw and functionalized bentonite samples, as described by Moraes $e t$ al. ${ }^{2}$

The initial acid leaching of the raw clay caused a certain distortion of the montmorillonite structure, and the interlayered distance $\left(\mathrm{d}_{001}\right)$ decreased from 1.53 to $1.26 \mathrm{~nm}$; additionally, the main reflection decreased in intensity and broadened (Figure 1, Bb). This distortion most likely occurred because of disorganization of the montmorillonite structural layers caused by the removal of the iron ions from the octahedral sheets and the removal of the exchangeable cations present in the interlayered region. However, this disorganization did not drastically affect the clay mineral layered structure. ${ }^{11}$

The oxidation and acidification of the - $\mathrm{SH}$ groups to $-\mathrm{SO}_{3} \mathrm{H}$ further accentuated the previously reported leaching process (Figure 1, Bc), and the main reflection $\left(\mathrm{d}_{001}\right)$ of montmorillonite nearly disappeared. No change was observed in the other minerals and clay minerals. This lack of change indicated that the process occurred only for the montmorillonite. ${ }^{9}$

The powder X-ray diffraction patterns (Figure 1) of the raw $(\mathrm{Va})$, acidified $(\mathrm{Vb})$ and functionalized vermiculite $(\mathrm{Vc})$ revealed the presence of vermiculite and quartz in the sample.

In contrast to bentonite, it was observed the disappeared of the main reflection of the vermiculite after the acid treatment, indicating a total collapse of the vermiculite structure. This collapse most likely occurred because of the higher disorder of the layers caused by the intense leaching of the ions present in the crystal network (Table 1). This leaching resulted in the formation of a type of cluster, which is corroborated by the presence of background characteristic of amorphous silica (region $2 \theta=17-31^{\circ}$ ) present in the diffractogram..$^{10,17}$

The insertion of the functionalizing agent caused regeneration of the vermiculite structure, and reflection related to the basal spaces reappeared (Figure 1, Vc). Only a small decrease was observed in the interlayer space $\left(\mathrm{d}_{002}\right)$, from $1.42 \mathrm{~nm}$ (Figure 1, Va) to $1.37 \mathrm{~nm}$ (Figure 1, Vc), in addition to the relative decrease in the intensities.

The small decrease in the molar ratio of the main ions present in the montmorillonite structure (Table 1) showed that the acid attack applied on the sample was not enough to cause drastic structural modifications in this material. However, in vermiculite the observed opposite behavior can be contributing to its structural disorder reflecting in the observed amorphism (Figure 1, Vb). The reduction of the $\mathrm{Al}$ and $\mathrm{Fe}$ ions probably present in the octahedral sheet can influence in the increase of the charge of the layers of the mineral.

The TGA curves of the raw bentonite (Figure 2a) exhibited a mass loss of approximately $11 \%$ between 35 and $220{ }^{\circ} \mathrm{C}$, whereas the mass loss for the functionalized material in the same temperature interval was approximately $5 \%$. In both cases, this mass loss most likely corresponded to the release of water, both adsorbed on the surface and coordinated to exchangeable cations. ${ }^{9}$ The second mass loss observed between 350 and $650{ }^{\circ} \mathrm{C}$ reached $3.5 \%$ in the raw bentonite and seems to be caused by the dehydroxylation reactions of montmorillonite with high iron content. ${ }^{18}$ For the functionalized material (mass loss $>8 \%$ ), the second mass loss must correspond to the dehydroxylation reactions 


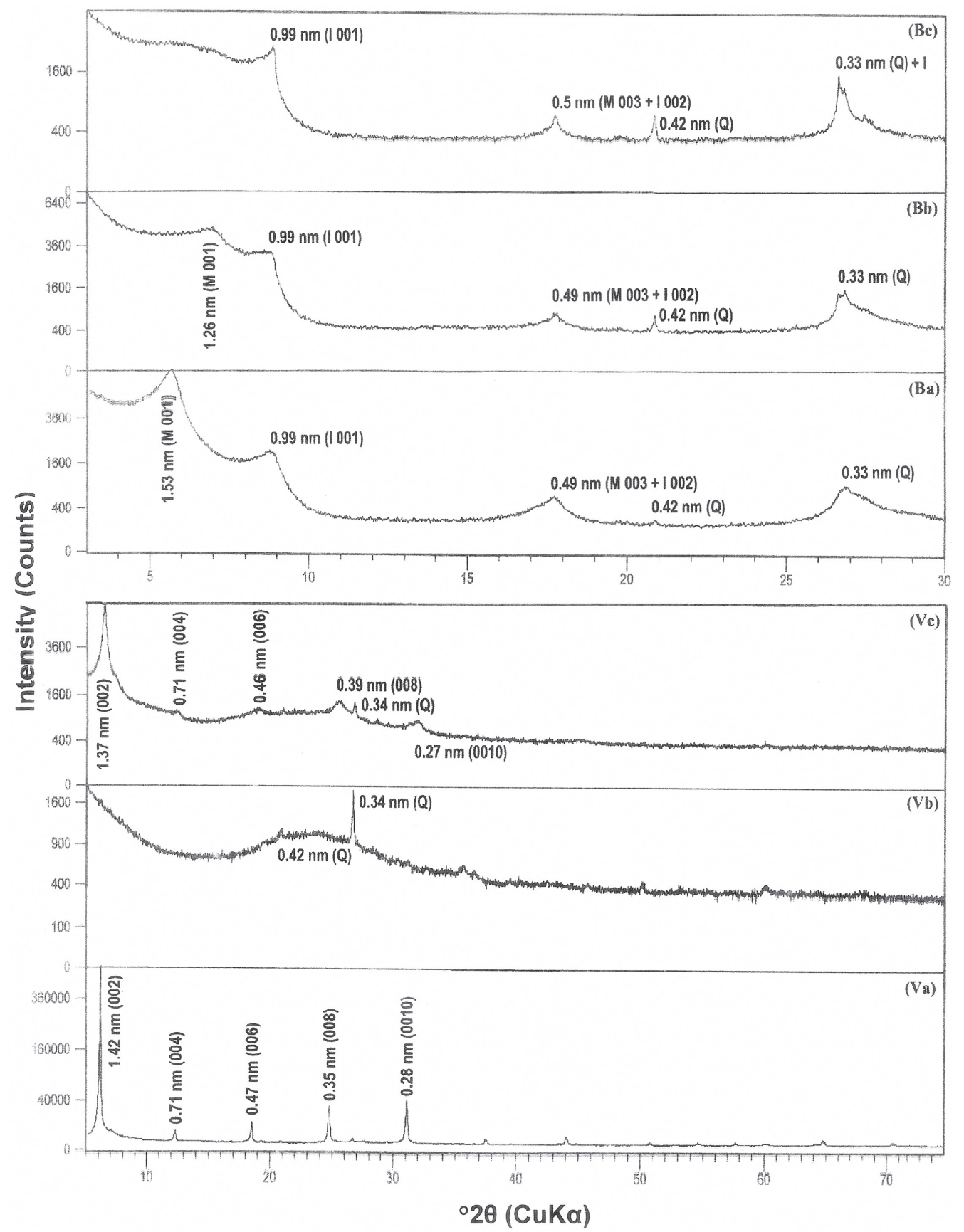

Figure 1. X-ray diffraction patterns of the raw bentonite (Ba) and raw vermiculite (Va), H-bentonite $(\mathrm{Bb})$ and $\mathrm{H}$-vermiculite $(\mathrm{Vb}), \mathrm{H}-\mathrm{bentonite-SO} \mathrm{H}_{3} \mathrm{H}(\mathrm{Bc})$ and $\mathrm{H}$-vermiculite- $\mathrm{SO}_{3} \mathrm{H}(\mathrm{Vc})$ samples. I: illite, $\mathrm{M}$ : montmorillonite, Q: quartz.

Table 1. The molar ratio of $\mathrm{Al} / \mathrm{Si}, \mathrm{Fe} / \mathrm{Si}, \mathrm{K} / \mathrm{Si}, \mathrm{Mg} / \mathrm{Si}$ and $\mathrm{Ca} / \mathrm{Si}$ of the raw and acidified samples $\left(2 \mathrm{~mol} \mathrm{~L}^{-1}, 4 \mathrm{~h}\right)$

\begin{tabular}{lccccc}
\hline \multirow{2}{*}{ Sample } & \multicolumn{5}{c}{ Molar ratio $\left(\mathrm{mol} \mathrm{mol}^{-1}\right)$} \\
\cline { 2 - 6 } & $\mathrm{Al}$ & $\mathrm{Fe}$ & $\mathrm{K}$ & $\mathrm{Mg}$ & $\mathrm{Ca}$ \\
\hline Raw bentonite & 0.25 & 0.09 & 0.11 & 0.06 & 0 \\
H-Bentonite & 0.25 & 0.08 & 0.11 & 0.05 & 0 \\
Raw vermiculite & 0.26 & 0.13 & 0.01 & 0.66 & 0.03 \\
H-Vermiculite & 0.02 & 0.01 & 0 & 0.05 & 0 \\
\hline
\end{tabular}

and the decomposition of the functional groups inserted in the clay mineral support. ${ }^{9}$

These statements could be confirmed from the DTA (differential thermal analyses) curves for both materials by the appearance of endothermic peak attributed to the water loss, the dehydroxylation reactions, and the decomposition of the functionalizing agent.

In the TG curves for the raw vermiculite (Figure 2b), showed the first mass loss of approximately $14 \%$ observed between 35 and $260^{\circ} \mathrm{C}$, the loss was attributed to the release 


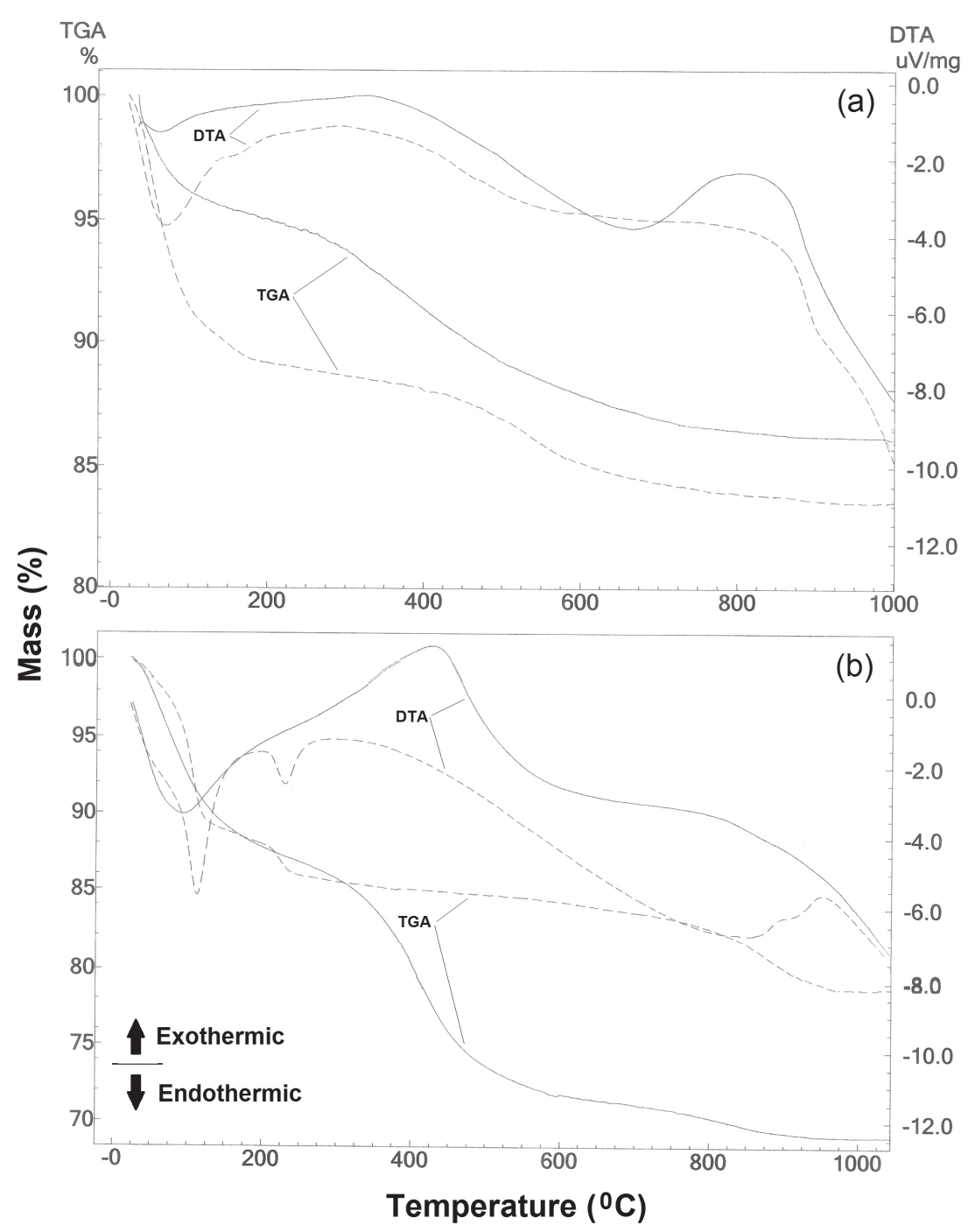

Figure 2. TGA curves of the (a) (----) raw bentonite and (-) H-bentonite- $\mathrm{SO}_{3} \mathrm{H}$ samples; (b) (----) raw vermiculite and (-) $\mathrm{H}$-vermiculite-SO${ }_{3} \mathrm{H}$ samples.

of interlayered and surface-adsorbed water molecules. The dehydroxylation reactions occurred in the raw vermiculite at approximately 700 to $950{ }^{\circ} \mathrm{C}$ with a mass loss of approximately $4 \% .^{19,20}$

In the functionalized sample, the loss was $31 \%$ between 35 and $950{ }^{\circ} \mathrm{C}$. The mass loss occurred almost immediately for the functionalized material in which the bonds may be weakened by the structural disorder by the leaching process. This mass loss resulted from the amount of water adsorbed, the dehydroxylation of the vermiculite and the decomposition reactions of the functionalizing agent.

According to the IUPAC classification, ${ }^{21}$ the raw bentonite and vermiculite samples exhibited a type I $\mathrm{N}_{2}$ adsorption/desorption isotherm (Figure 3), which is characteristic of microporous solids, with hysteresis type H3. This hysteresis is usually found in solids made of particle aggregates or agglomerates that form non-uniform pores with slit shapes, plates or sharpened particles. ${ }^{21}$
After the functionalization, the bentonite and vermiculite retained the same type of isotherm and hysteresis (Figure 3), the reduced hysteresis area indicates a reduction in the pores that were initially present. ${ }^{10}$

The results for the major textural properties of the raw, acidified and functionalized samples (Table 2) revealed that for the acidified bentonite, the increase in the specific surface area after the leaching process most likely resulted from replacement of exchangeable cations by protons; this exchange contributed to the increase of the pore volume. ${ }^{9}$ For the acidified vermiculite, the increase in both the specific surface area and the pore volume after the acid leaching could be explained by the disorganization of the structure (Figure 1, Vb). ${ }^{10}$

For the bentonite the functionalization process occurred with a decrease in the specific surface area and the pore volume; these decreases were most likely caused by the occupation or obstruction of the pores by the 


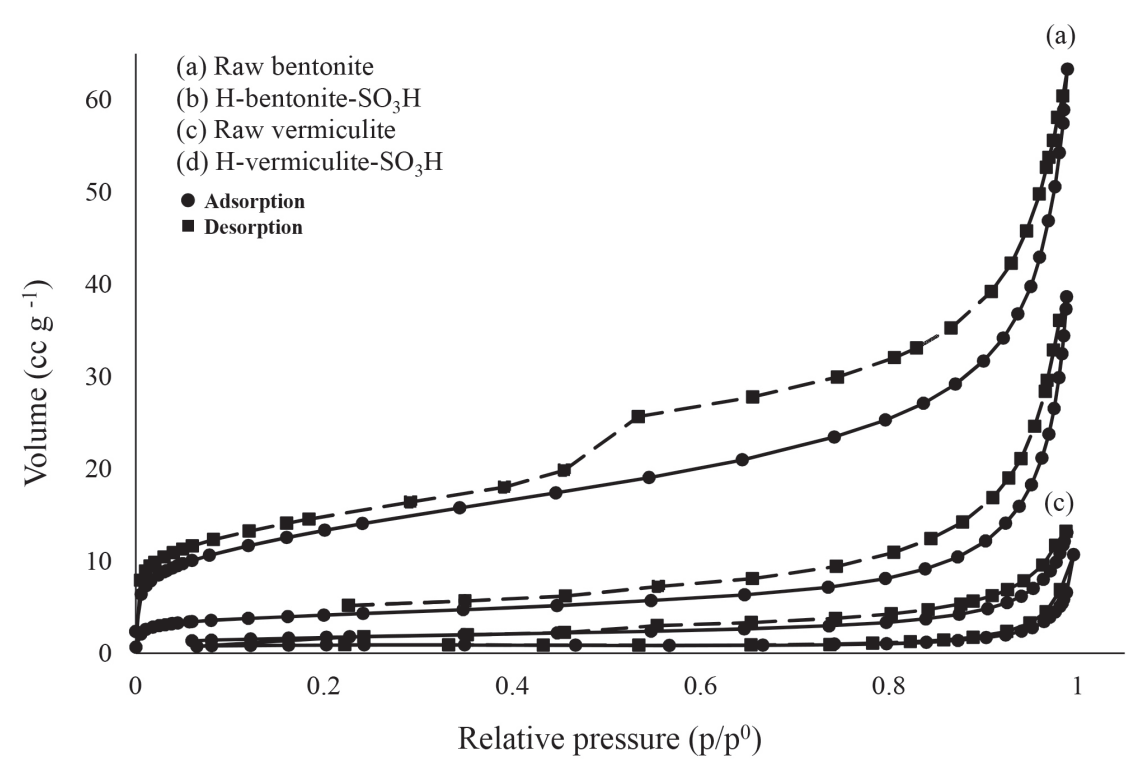

Figure 3. $\mathrm{N}_{2}$-Isotherms of raw bentonite and vermiculite, $\mathrm{H}$-bentonite- $\mathrm{SO}_{3} \mathrm{H}$ and $\mathrm{H}$-vermiculite- $\mathrm{SO}_{3} \mathrm{H}$.

Table 2. Comparison of effects of functionalization on some physical-chemical properties of the samples

\begin{tabular}{lcccc}
\hline Sample & $\mathrm{S}_{\mathrm{BET}} /\left(\mathrm{m}^{2} \mathrm{~g}^{-1}\right)$ & $\mathrm{Vp} /\left(\mathrm{cm}^{3} \mathrm{~g}^{-1}\right)$ & Surface acidity $/\left(\mathrm{mmol} \mathrm{H}^{+} \mathrm{g}^{-1}\right)$ & $\mathrm{S}$ content $/$ wt.\% \\
\hline Raw bentonite & 46 & 0.08 & 0 & 0 \\
Bentonite- $\mathrm{SO}_{3} \mathrm{H}^{\mathrm{a}}$ & 31 & 0.04 & 0.5 & 0.7 \\
H-Bentonite & 101 & 0.10 & 0.3 & 0 \\
H-Bentonite- $\mathrm{SO}_{3} \mathrm{H}$ & 14 & 0.05 & 0.6 & 2.3 \\
Raw vermiculite & 6 & 0.02 & 0 & 0 \\
H-Vermiculite & 198 & 0.22 & 0.6 & 0.2 \\
H-Vermiculite- $\mathrm{SO}_{3} \mathrm{H}$ & 3 & 0.01 & 0.9 & 7.3 \\
\hline
\end{tabular}

${ }^{a}$ Moraes et al. ${ }^{9} \mathrm{~S}_{\mathrm{BET}}$ : Brunauer-Emmett-Teller specific surface area; Vp: pore volume.

functionalizing agent. ${ }^{9}$ In the functionalized vermiculite, based on the reorganization of the layers, a new structure formed with an interlayered distance smaller than that of the raw vermiculite. The formation of the new structure can be monitored in the XRD pattern (Figure 1, Vc) and contributed to the reduction of the specific surface area and the pore volume.

The acidity and sulfur content of the bentonite (Table 2) could be correlated with the amount of functionalizing agent fixed to the target material, as observed in Moraes et al. ${ }^{9}$ These values also indicated that the acid treatment before the functionalization process increased the amount of functionalizing agent fixed to the montmorillonite structure. In particular, when the same procedure was applied to the vermiculite, it created a material with an acidity higher than that of the materials that underwent the functionalizing process only, such as MCMs, SBA-15 and the functionalized bentonite..$^{9,22}$

All of these results suggest that the proposed method for functionalization of these materials created a higher acidity than the previous procedures; therefore, these materials could be used as catalysts in organic reactions that involve Brønsted acidity.

\section{Catalytic tests}

The catalytic tests with the functionalized materials, H-bentonite- $\mathrm{SO}_{3} \mathrm{H}, \mathrm{H}$-vermiculite- $\mathrm{SO}_{3} \mathrm{H}$, Amberlyst 36, and the results for the uncatalyzed reactions were realized with the objective to study the catalytic activity of these materials in the production of propyl acetate ester (addition of acetic acid to propan-1-ol) according to the procedure described in Moraes et al. ${ }^{9}$

The results showed that, compared to the uncatalyzed reaction (Figure 4), the most effective catalyst for conversion of the reagents was Amberlyst 36 (surface acidity measured $=5.2 \mathrm{mmol} \mathrm{H}^{+} \mathrm{g}^{-1}$ ) because after $14 \mathrm{~h}$ the reaction seems to have reached equilibrium with a $68 \%$ yield. Elapsed same time, the yield of the uncatalyzed reaction was $49 \%$. The second best yield was achieved 


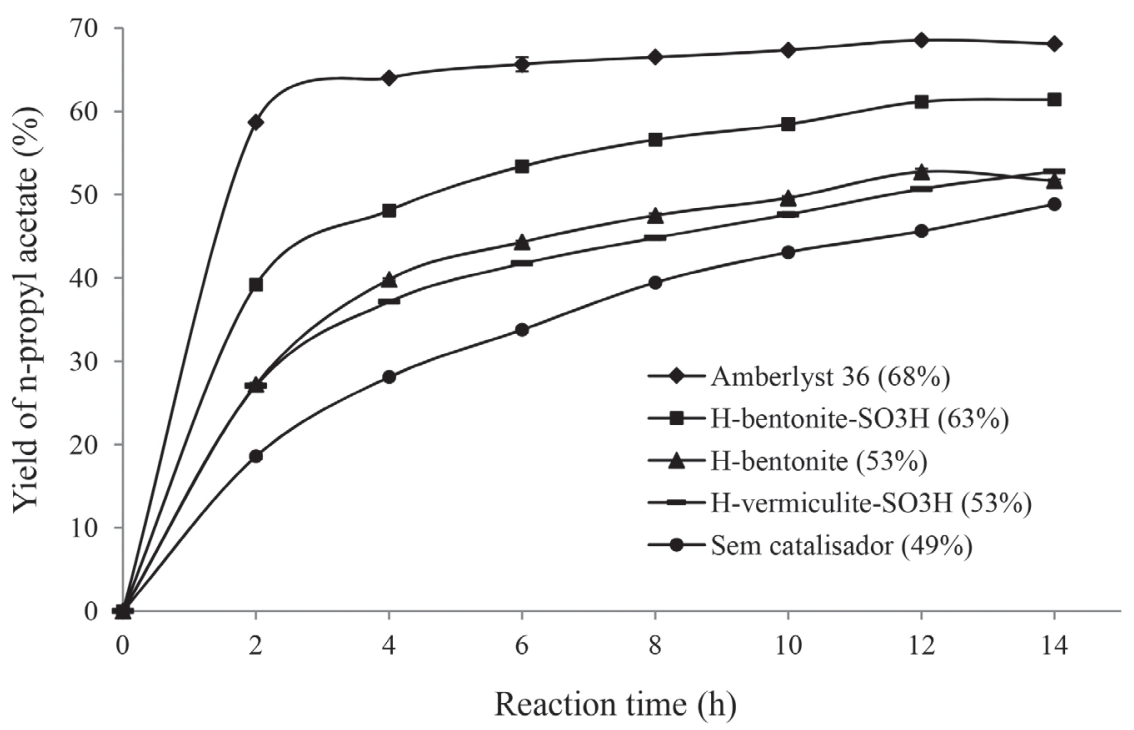

Figure 4. Catalytic performance of catalysts at $100^{\circ} \mathrm{C}$.

by the H-bentonite- $\mathrm{SO}_{3} \mathrm{H}(63 \%)$, and the yield for both materials did not differ greatly. In the catalytic test carried out with H-bentonite (surface acidity $=0.3 \mathrm{mmol} \mathrm{H}^{+} \mathrm{g}^{-1}$; $\mathrm{S}$ content $=0$ ), the yield after $14 \mathrm{~h}$ of reaction was $53 \%$.

Despite the bentonite subjected to previous acid treatment (H-bentonite- $\mathrm{SO}_{3} \mathrm{H}$ ) had identical final yield to the conventional bentonite present in Moraes et al. ${ }^{9}$ (bentonite- $\mathrm{SO}_{3} \mathrm{H}$ ), the increased acidity led to a higher velocity in reaction test, mainly in the first two hours of reaction.

The $\mathrm{H}$-vermiculite- $\mathrm{SO}_{3} \mathrm{H}$ was not as efficient catalyst (53\% yield), although the total acidity of this material was higher than that of the H-bentonite- $\mathrm{SO}_{3} \mathrm{H}$. This might be explained by the intense leaching process that drastically altered the structure of vermiculite, as showed by the XRD patterns. The reduction of iron ions in the vermiculite structure may be contributing to the increase in the charge of the layers, inhibiting the liberation of the $\mathrm{H}^{+}$ions in the same form as in the bentonite. Thus, the results seem to indicate that the total acidity and the amount of MPTS groups are not the only factors that influence the catalytic activity.

Additionally, when the $\mathrm{H}$-vermiculite- $\mathrm{SO}_{3} \mathrm{H}$ was used, an equilibrium state was not achieved. This result indicates that the reaction time was insufficient.

The catalytic performance presented by $\mathrm{H}$-vermiculite$\mathrm{SO}_{3} \mathrm{H}$, justify the not realization of further investigation with respect to other parameters related to the reaction test. However, with respect to textural and functional properties presented by the vermiculite been higher than bentonite suggests a more detailed investigation with respect to factor which inhibited its performance as catalyst, in order to create a more catalytically efficient material.

\section{Conclusions}

In addition to bentonite, the preparations of an organomaterial with another phyllosilicate mineral were successful. This preparation demonstrates that the synthetic process is satisfactory and suggests tests of other naturally occurring clay-bearing materials, especially those available in the region. Before functionalization, the creation of new active sites from the structural defects caused by the acid leaching process in bentonite allowed more functionalizing agent to be anchored. This process resulted in an increase of the total acidity of the material relative to the sample that was directly functionalized. The results obtained serve to encourage its further use in adsorption applications or catalysis.

The tests also showed that in this type of reactions, the functionalized bentonite is a more efficient catalyst than the functionalized vermiculite; this result is corroborated by the higher yield and faster chemical equilibrium achieved for the $\mathrm{H}$-bentonite- $\mathrm{SO}_{3} \mathrm{H}$ than for the $\mathrm{H}$-vermiculite- $\mathrm{SO}_{3} \mathrm{H}$. The increase in acidity of bentonite subjected to previous acid treatment (H-bentonite- $\mathrm{SO}_{3} \mathrm{H}$ ) was important because it led to an increase in the reaction test velocity.

\section{Acknowledgments}

The authors thank the PROPESP/UFPA, PARD and LAPAC for financial support.

\section{References}

1. Zhang, D.; Zhou, C.; Lin, C.; Tong, D.; Yu, W.; Appl. Clay Sci. 2010, 50,1 . 
2. Moraes, D. S.; Angélica, R. S.; Costa, C. E. F.; Rocha Filho, G. N.; Zamian, J. R.; Appl. Clay Sci. 2010, 48, 475.

3. Paz, S. P. A.; Angélica, R. S.; Neves, R. F.; Clays Clay Miner. 2012, 60, 265.

4. Oliveira, A. N.; Costa, L. R. S.; Pires, L. H. O.; Nascimento L. A. S.; Angélica, R. S.; Costa, C. E. F.; Zamian, J. R.; Rocha Filho, G. N.; Fuel 2013, 103, 626.

5. Centi, G.; Perathoner, S.; Microporous Mesoporous Mater. 2008, 107, 3.

6. Vaugham, D. E. W.; Catal. Today 1988, 2, 187.

7. Figueras, F.; Catal. Rev.: Sci. Eng. 1988, 30, 457.

8. Nascimento, L. A. S.; Tito, L. M. Z.; Angélica, R. S.; Costa, C. E. F.; Zamian, J. R.; Rocha Filho, G. N.; Appl. Catal., B 2011, 101, 495.

9. Moraes, D. S.; Angélica, R. S.; Costa, C. E. F.; Rocha Filho, G. N.; Zamian, J. R.; Appl. Clay Sci. 2011, 51, 209.

10. Chmielarz, L.; Kowalczyk, A.; Michalik, M.; Dudek, B.; Piwowarska, Z.; Matusiewicz, A.; Appl. Clay Sci. 2010, 49, 156.

11. Guimarães, A. M. F.; Ciminelli, V. S. T.; Vasconcelos, W. L.; Appl. Clay Sci. 2009, 42, 410.

12. Paiva, L. B.; Morales, A. R.; Díaz, F. R. V.; Appl. Clay Sci. 2008, 42,8 .
13. Santos, S. S. G.; Silva, H. R. M.; Souza, A. G.; Alves, A. P. M.; da Silva Filho, E. C.; Fonseca, M. G.; Appl. Clay Sci. 2015, 104, 286.

14. Tributh, H.; Lagaly, G. A.; GIT Fachz. Lab. 1986, 30, 771.

15. Dijs, I. J.; van Ochten, H. F. L.; van der Heiden, A. J. M.; Geus, J. W.; Jenneskens, L.W.; Appl. Catal., A 2003, 241, 185.

16. AOCS; Official Method Cd 3d-63: Acid Value; American Oil Chemists' Society, Urbana, 2003.

17. Temuujina, J.; Okadab, K.; MacKenzie, K. J. D.; Appl. Clay Sci. 2003, 22, 187.

18. Brigatti, M. F.; Clay Miner. 1983, 18, 177.

19. Brigatti, M. F.; Colonna, S.; Malferrari, D.; Medici, L.; Poppi, L.; Appl. Clay Sci. 2005, 28, 1.

20. Malferrari, D.; Brigatti, M. F.; Marcelli, A.; Chu, W.; Wu, Z.; Appl. Clay Sci. 2010, 50, 12.

21. Leofanti, G.; Padovan, M.; Tozzola, G.; Venturelli, B.; Catal. Today 1998, 41, 207.

22. Rác, B.; Nagy, M.; Pálinkó, I.; Molnár, A.; Appl. Catal., A 2007, $316,152$.

Submitted: February 26, 2017

Published online: July 31, 2017 